Published in final edited form as:

Am Anthropol. 2001 March 1; 29(1): 30-57. doi:10.1525/eth.2001.29.1.30.

\title{
The Fragility of Healing
}

\author{
Cheryl Mattingly and \\ Professor with the Department of Anthropology and Department of Occupational Science and \\ Therapy, University of Southern California \\ Mary Lawlor \\ Associate Professor with the Department of Occupational Science and Therapy, University of \\ Southern California
}

\section{Abstract}

This article explores a paradox-the simultaneous cultivation and suppression of "healing dramas" by pediatric rehabilitation therapists. Dramatic moments are defined as ones in which the routine exercises and treatment activities of therapeutic practice are transformed into narrative plots. These improvisational plots involve multiple characters, risks, suspense, and above all, a heightened sense that something is at stake. Experience itself becomes the focus of attention for the patient. Based upon ethnographic research in Chicago and Los Angeles, this article offers an anatomy of two such moments, investigating not only how healing dramas are constructed between patients and healers but how and why institutional discourses and practices invite their abandonment.

When Oliver Sacks fell off a mountain, he found himself in a hospital with a leg that would not move. This temporary paralysis was no mere matter of torn tendons, but an injury to the nerves themselves. "The neural traffic had stopped, so to speak," Sacks tells us, "and the streets of the city were deserted and silent" (1987:65). He appears to his doctors and therapists as a patient with a leg injury, a local affair, but he knows better. He has lost his leg altogether, although, strangely, it is still attached to him. With this loss, his very spirit, his imagining, intending, purposeful self is endangered: "I had lost the power to 'call' to a part of myself, the power to call on a part of myself" (1987:65). It becomes painfully clear to Sacks that what he had initially viewed as a peripheral breakdown was, in fact, a breakdown at the center of things, "not just a lesion in my muscle, but a lesion in me" (1987:66). This article considers the role of rehabilitation for those who, in one way or another, confront lesions that run all the way to the center of themselves, when bodies become sources of pain or humiliation, or when they have cracked to the core. We investigate a puzzle Sacks raises in trying to understand the perspective of his healers. While he finds that his recovery is full of adventures and dramas, his healers see things as routine. How can this be? he wonders indignantly. How can they speak of his recovery as "uneventful" when "recovery is events, a series of wonderful, unpredictable events ... advents, which are births and re-births" (1987:154)?

In this article, we take up Sacks's puzzle, drawing from our own ethnographic research among occupational therapists, physical therapists, physicians, nurses, and other pediatric health professionals who treat children who are seriously ill or disabled. We will argue that the puzzle Sacks notes becomes ever more complex as one attends to the daily practices, discourses, and ideologies of these professionals. We have found the systematic suppression of certain kinds of dramas in clinical settings, especially dramas in which a central character is the patient as a complex, socially situated person with his or her own illness experience and biography. But - and here is the mystery that lies at the core of this article-we have also found sustained efforts to cultivate healing dramas which speak to such a person. Among occupational therapists (those health professionals we know best), there is even a discourse in the form of archetypal "best case" stories that stresses the centrality of such dramas to good practice. 
Sometimes, in other words, healers in Western biomedical settings do seem to recognize that recovery is constituted through "events," and "rebirths"; and this recognition translates into conscious efforts to support and foster such recovery dramas. However, support is often short lived, undermined or aborted altogether. Even when such fostering occurs, the treating practitioner who in one moment helps to create a powerful healing drama may in the next moment deny that she has done so, or doubt her own wisdom in pursuing such a path. This article investigates the rise and fall of healing dramas. When and why are they nurtured by healers? What is it about the nature of rehabilitation practices and clinic culture that makes these dramas so fragile, so easily relinquished or neglected? Why do they crop up in the informal storytelling of some professionals but not in the more "official" discourses, such as the medical chart?

\section{HEALING AS DRAMA}

Before considering this mystery, it is worth identifying the qualities associated with the "eventful moment" of recovery. To consider healing dramas in the context of rehabilitation and how they might differ from other "noneventful" moments of recovery, we return briefly to Sacks and his leg injury, asking how he rediscovers and reclaims a leg that seemed for so long to be not merely injured, but vanished altogether. At first he begins to feel "crackles" and "flashes" in his leg, this electrical activity betokening neurological life in this formerly absent region. However, these impulses are not connected to him, he tells us, because they are disconnected from all will, intention, or idea. The day finally comes when Sacks's therapist insists he stand. He is to resume his uprightness, to overcome his passive, recumbent posture. But he needs to imagine how to move his leg, and this is part of his problem. How is Sacks's imagination to be sparked? What will transform a leg electrified to a leg in action? As it turns out, it is music which gives life to his leg. One day while trying to walk, he suddenly recalls, or more accurately his body recalls, a piece by Mendelssohn he had happened to hear the day before, not even a piece he much liked. In this embodied remembering his leg awakens. "Until the music, there had been no feeling whatever," he writes. "Then, all of a sudden, with no warning whatever, ... came music, warm, vivid, alive, moving, personal. ... And in that moment, when the body became action, the leg, the flesh became quick and alive, the flesh became music, incarnate solid music" (1987:147-148).

This walk, joyously executed, transforms his first music-less, robotic steps into his own natural rhythm. It marks a turning point in his own recovery. This moment becomes the stuff of which stories can (and will) be told. And what of this momentous walk? Here we have the most ordinary thing taking on dramatic status precisely at the moment when it resumes its natural place as habitual, unconscious action. His walk shifts from exhausting calculation to thoughtless movement. And what does Sacks recover in this transformative, thoughtless moment? More than a leg. It is himself that is recovered: "It was the triumphant return of the quintessential living 'I'” (1987:149).

This music, recollected by his body kinesthetically through his first faltering steps, engenders an experience which bears the mark of a narrative moment with its own dramatic structure. The experience Sacks describes is something shaped. It presents itself to him as an experience, in the language of a certain branch of phenomenology (Dilthey 1989; Gadamer 1975). He is not merely living through something, surviving something. He is having an experience that can be distinguished from others, that can be partly disclosed in textual form-as, in fact, a story. Every experience has something in it of the idea of adventure, Simmel argued. His experience constitutes a story in the making, an adventure worth telling a story about.

But notice the peculiarly ambiguous quality to "experience" here. Whatever Sacks can later say, quite obviously his words can never capture the experience itself as something felt in his 
body. Even his memories of these dramatic moments are not simple representations of a past. And, yet, he has had a singular experience that is indeed preserved in memory and therefore can be returned to, recalled, even reheard, and refelt. Experience, when it emerges as a unique memory-making event, bears an ambiguous quality. It has some of the qualities of an object, inscribed in memory as a particular something that can be re-presented. And, yet, it is also fleeting and, as Gadamer (1975) says, "inexhaustible" in its potential meaning. It resists representation. Significant experiences can never be captured by any images, any "objects" preserved in text or other medium. The antirepresentational qualities of significant experience also have to do with their practical capabilities; meaning is never fixed because it changes a future, and that future will remake the meaning of the past. Sacks's experience of being "musicked along" by Mendelssohn is not merely remembered, it is remembered as transformative, slicing his life into a "before" and "after." This significant experience, preserved for all his life, becomes generative of new experiences (including the writing of a book about them) that, in turn, imbue new and different meanings on that one moment of recovery. Yet this rebirth via Mendelssohn is also evanescent. It disappears, never to be fully recaptured or relived.

The connection between significant experience and narrative form has been most extensively explored within philosophy, particularly among those influenced by phenomenological and hermeneutic traditions. Some have suggested that experience itself, or at least significant experience, has narrative form (Carr 1986, 1997; Crites 1997; Maclntyre 1981; Olafson 1979; Ricoeur 1984, 1987). Related arguments concerning the human propensity to understand and interpret ongoing actions by seeing them as parts of unfolding narratives have arisen in various branches of cognitive and developmental psychology (cf. Bruner 1986, 1990,1991; Polkinghorne 1988). Through an amalgam of psychoanalytic theory, transactional models of development, and clinical experiences drawn from infant mental health interventions, Stern $(1994,1995)$ argues that ongoing subjective experiences in which motives are enacted have a "temporal feeling shape" and are represented in "protonarrative envelopes" (1994:11) that provide a holistic representation of the subjective and emergent properties of experience. This proposed unit of protonarrative envelopes, which Stern also describes as a

"prestory" (1995:85), also contributes to a narrative-like representational form Stern describes as a "schema of being with another in a certain way" (1994.12). Stern's description links narrative not only to interior experience but also to the social world for he argues that significant subjective experiences (of infants) are interpersonal.

Within anthropology, the link between drama, narrative, and healing has been explored by those who analyze non-Western and alternative healing rituals. However, there has been little attention to the formal qualities of narrative and those significant experiences that are often at the heart of the healing ritual. Anthropological studies of healing rituals underscore that most significant experiences do not simply befall humans but are carefully crafted and staged, sometimes even rehearsed. They are, in short, created as well as received. Both creation and reception are a social affair. Healing rituals across a wide array of cultures have been noted for features which, we will try to show, are also integral to the power and efficacy of these "hidden dramas" within biomedical practice:

1. There is a heightened attention to the moment, an "existential immediacy" that gives an authority and legitimacy to the activity (Csordas 1996, 1994; Desjarlais 1996; Schieffelin 1996).

2. A multiplicity of communicative channels carry the meaning, creating a "fusion of experience" (Briggs 1996; Tambiah 1985).

3. Aesthetic, sensuous, and extralinguistic qualities of the interaction are accentuated (Jackson 1989; Laderman 1996; Stoller 1989, 1996, 1997). 
4. The intensification of experience is socially shared, and it emerges through mutual bodily engagement with others (Danforth 1989; Hughes-Freeland 1998; Kapferer 1983, 1986; Schechner 1990).

5. Healing actions are symbolically dense, creating images that refer both backward and forward in time - the patient is located symbolically in history (Kendall 1996).

6. Efficacy is linked to potential transformations of the "patient" and sometimes a larger social community (Kendall 1996; Turner 1969, 1986a, 1986b; Turner 1992).

For a more extended discussion of these qualities as aspects of Western biomedical practice, see Mattingly $1998,{ }^{2000 .}$

The ephemeral character of significant and memory-making experience that has intrigued philosophers takes on added complexities when examined from an anthropological standpoint, in which the role of culture and social context is factored in. The fleeting quality of Sacks's recovery experience is no mere existential given. It is abetted because Sacks's experience is largely private, interior, despite strenuous efforts to involve those around him. His doctors, nurses, and therapists are unaware (or find insignificant) what has happened to him. Sacks has his narrative moments, his astonishing experiences, but he apparently has them all by himself. He experiences dramas - stories in the making - where the professionals see only a mundane, predictable path. When he steals a look at his chart and finds written "uneventful recovery," he concludes that his healers are "mad." In turning to our own research, we explore the aesthetic, embodied, highly charged, and narratively shaped qualities of recovery events and their centrality to healing. The "madness" shows up as well, a point we also explore in the context of our own research in pediatric rehabilitation practice.

\section{HIDDEN DRAMAS IN PEDIATRIC PRACTICE}

Our data are drawn from two ethnographic studies of pediatric health care, one in Chicago and the second in Los Angeles. The Chicago study, conducted between 1994 and 1996, involved ten pediatric occupational therapists, their young patients and, where possible, parents and other key family members. We carried out the study in two clinical sites located in the heart of the city, one in the downtown area, the other on the near west side. These two hospitals serve low-income populations overwhelmingly African American and Mexican American. We observed and sometimes videotaped clinical encounters. We also interviewed therapists and family members, audiotaping and subsequently transcribing these interviews. The focus of the study was to examine "therapeutic partnering" with patients and families. Rehabilitation, particularly in outpatient pediatrics, requires high levels of collaboration and support among therapists, patients, and key family care givers who are asked to carry out "home programs" involving exercises and other therapeutic treatments. In this study, we were primarily focused on the therapist's perceptions of what constituted effective collaboration with children and families, how they went about trying to create it, and their perception of dilemmas and obstacles to their effectiveness. Where we were able to obtain permission from families, we separately interviewed parents (or primary family caregiver) and the children participating in the study.

The second study, located primarily in two clinical sites in Los Angeles, also addresses the issue of collaboration among health care providers, patients, and family members, but on a much larger scale. This seven-year study, begun in 1997 and still ongoing, is built upon the design and some findings that grew out of the Chicago research. It, too, examines communication and collaboration among children, health care practitioners and families. However, it is a much broader study in several senses. It focuses equally on health care professionals and the institutional cultures in which care takes place and on the children and families who receive services. Though we entered clinical sites through contacts with occupational therapists, and these professionals have been more extensively followed than 
other health care practitioners, the study includes a very broad array of health professionals: surgeons, oncologists, radiologists, pediatricians, social workers, nurses, nutritionists, physical therapists, speech therapists, health care aides, special educational teachers, and psychologists. It also goes well beyond the Chicago research by following children and families outside the clinical encounter into their homes, schools, and neighborhoods. In fact, while there is still extensive time spent at the clinic sites where the families were initially recruited, the central actors in the study are the 30 African American children and their families. Once families agreed to participate, health care professionals were recruited on the basis of their involvement with the children and families. Since the total sample is quite large (well over 500) and data collection tends to be intensive (with multiple interviews, observations, and videotapes), we have not been conducting this research alone. We have assembled a core research team that includes doctoral students in both anthropology and occupational therapy at the University of Southern California.

The longitudinal design has allowed us to follow children and families as they change. This, too, while making for a more complicated study, has offered us a much deeper understanding of what turns out to make a difference in the partnering efforts of health care professionals and families. It has enabled us to connect minute intense moments of "significant experience" and minor healing dramas which never show up in the medical chart to the lives of children and families beyond the clinical encounter.

The children in the Los Angeles study, like those in the Chicago study, do not share a single kind of disease or disability. Rather, they share certain commonalities of "illness experience," suffering from a serious, chronic illness or disability that requires frequent visits to an array of health care professionals, and substantial efforts by family members to provide care at home. In addition, since this study focuses exclusively on African American children, there is a shared ethnic or racial label. As might be expected, there is substantial diversity as well in the families that comprise our sample group. However, certain patterns appear across the cases. The importance of powerful healing dramas in the rehabilitation process, and their significance to children and families, for example, is broadly shared. Since the vast majority of health care providers in our sites are not themselves African American and are from middle and upper income strata, collaboration between professionals and families means connecting across cultural worlds and racial boundaries where wariness and suspicion often create a subtle undercurrent of tension.

The two cases we analyze were selected because they illustrate the dramatic and aesthetic qualities of quite ordinary treatment interventions in rehabilitation. Also, they reveal the paradox which is central to this article and figures prominently in our data: the way that healing dramas are at once cultivated and suppressed by pediatric health professionals. This paradox shows up in numerous forms. Treatment goals emphasize "fixing" or improving body parts but when practitioners describe what they think really matters about their interventions, they are likely to stress the importance of using therapy time to encourage dramatic transformations in the perspectives and practices of patients and family members. Occupational and physical therapists who are particularly adept at encouraging children to engage in highly creative activities, embedding exercises designed to "treat an arm" or "improve gross motor coordination" within imaginative scenarios that delight the children they treat, will speak dismissively of these efforts in subsequent interviews. "You know, with kids, you really have to motivate them or they won't work in therapy," they explain with some embarrassment when they have resorted to creative and playful treatment programs. Talking and playing are typically set against exercises, procedures, and other "real work" features of clinical practice such that the former are perceived to take time away from the latter. Clinicians facilitating powerful healing dramas readily discharge the children rather than make the case to colleagues or families for continued treatment. Short stays and early discharges are, of course, readily traced 
to a reimbursement system largely out of the hand of individual clinicians. The irony here is not that children are discharged too soon but that clinicians (at least occupational therapists and physical therapists) consistently abandon their own powerful work. That is, their own representations of their practice, even in interviews, are characteristically deeply ambivalent. Furthermore, their clinical actions and decisions are often marked by this same ambivalence.

The paradoxical movement to both cultivate and abandon healing dramas is explored in concrete ethnographic detail below. The clinicians who are the main protagonists in these dramas are occupational therapists. The children are from low-income, urban communities typical of the population served by the clinical sites. The children in the two cases both suffer not only from a disabling physical condition but arrive for treatment laden with a welter of behavioral and emotional disorders and these play a major role in the unfolding dramas.

\section{Felicia and the Raven-Haired Pocohontas}

One rainy day at an urban teaching hospital, we observed a session in which an occupational therapist, Penny, was treating a young teenaged girl of about 13 or 14. We will call her Felicia. Felicia had been referred by special educators at her school for treatment at this outpatient clinic. Once a week Felicia was bussed from school to the hospital for therapy. The therapist told us in a later interview something of the diagnostic history that brought her to occupational therapy. It included leukemia when she was eight or nine, which was in remission, seizure disorders, and a fuzzy psychiatric diagnosis, which the therapist variously called "oppositional defiant disorder" and "conduct disorder." The particular problems Penny, the therapist, was to address were some delays in fine motor and visual motor skills. Felicia's teachers wanted the therapist to work especially on her handwriting, which was very messy.

At the time of the session, the therapist had known Felicia for about two years. They had a very close relationship. Felicia was the only one in her school who got to go to occupational therapy and this made her feel special. She also enjoyed what they did in occupational therapy, which was mostly a lot of craft projects and some handwriting and computer writing work. While Felicia missed school frequently, she never missed Fridays. The therapist said that she would "always beg her father on Thursday night to make sure that he woke her up for Friday because she didn't want to miss O. T."

Here is the scene we observed when we first met Felicia. In she walks to the occupational therapy treatment room, a bouncy and rather large girl, a little unkempt but with a tremendously friendly smile. There is an initial struggle between Penny and Felicia about which activity they will do in therapy. Penny has offered Felicia the option of one among several possible prepackaged sand-painting kits. The outside boxes show pictures of the finished paintings (all Disney characters from various movies) and Felicia pores carefully over each one. This initial scene between Penny and Felicia is keyed playfully but with a serious under-tone, in which the therapist is trying to speed Felicia along, clearly with an eye to their limited time. Felicia makes a great show of indecisiveness, and even seems to be teasing Penny. "Jeez, don't rush me!" she says with a great laugh and a conspiratorial grin to the two unknown observers huddled in the corner watching the scene with their notebooks open. Finally, things settle down, and we see that, at the therapist's urging, they are going to do a sand painting of Pocohontas. This Pocohontas, in the finished illustration featured on the cover, is a very pretty, slim girl of about 16 with many brightly colored birds circling her head like a halo. All about her is a very blue sky. Penny and Felicia settle at a small table with their kit and now prepare to get started. They immediately contest just how they are going to organize the task. Shall they line up the colored packets of sand by their numbers (Penny's preference)? Or by those which just seem to fit together (Felicia's scheme)? 
Finally, 10 or 15 minutes into the session, things get going. Felicia gradually becomes absorbed, pouring the sand with painstaking care, surveying her work with a critical eye. She appears to have forgotten her audience entirely. She is silent, intent, crafting her picture with occasional guidance from the therapist. A few minutes later, they color Pocohontas's hair, which makes up a large patch of the picture. This is glossy, shiny, black hair. Silky and long. The therapist says to Felicia, "She's very pretty." They both agree. "She has hair like yours!" Penny then tells her. Cheryl and Mary later discuss their own surprise. The therapist is right. Felicia may not be the beautiful Pocohontas, but she has exactly her hair, the same silky blue-black hair of this fairy tale girl surrounded by these lovely birds. When Mary and Cheryl reconnoiter later in the hospital cafeteria, they return to this moment in this session. Cheryl says, "So, they weren't really painting Pocohontas; they were creating a mirror, a fairy-tale mirror, of whom Felicia might be. The beautiful girl she is not, but might imagine herself to be. They are making a mirror, an image of one possible future Felicia." Cheryl and Mary suddenly recognize that Felicia could be quite pretty. They re-see her in their minds. They begin to see this session as a place where pictures are made. These are not, most importantly, literal ones, but rather imaginative ones where images are created and negotiated.

The activities of Penny and Felicia create another sort of image, a kinesthetic image of concentration and focus required to craft something Felicia finds worth creating. Felicia shifts from being a bouncy but tendentious girl to one who concentrates carefully, head bent, completely focused on her task. A girl who has the skills and desire to create something that brings her pleasure-someone who can sit still long enough to do a good job. And the picture itself, however foolish and fantastical, offers another image. It is not just any picture, but a picture of a girl not so much older than Felicia herself, and with that same abundance of rich black hair. Felicia, when she smiles, even gives off something of Pocohontas' cheery brilliance. (In fact, there is something preferable about the impishness of Felicia's grin when compared to the blank beauty of the Walt Disney character.) But look at Pocohontas! Loved by all, even the birds. Free to wander under a clear sky. Not trapped in a dark, cold apartment babysitting three young children and fattening up on potato chips, the image Penny sees when she looks fearfully into Felicia's future. Pocohontas may have her troubles but her world certainly sparkles. Penny doesn't mean to pass along fairytales to Felicia. In fact, it bothers her that Felicia, at her age, is still so enamored of these magical figures. She notes in a later interview that Felicia "always like tends to pick things that are pretty like that ... more immature for her age ... and fairy-tale scenes." And Penny worries a little that she allows Felicia to select therapeutic activities which are "seven, eight, nine-year-old type things ... if you compare her to other girls 14 and 15, you know, they'd be more into music or whatever."

Yet she helps Felicia to create magical and pretty worlds, magical girls like Pocohontas in these moments of therapy time that have come to mean so much to Felicia. Though Penny doesn't quite seem to realize it, what gets created here is not so much a picture but an event, an event that signals possibility. Here is a little drama with qualities associated with healing rituals: a multimedia, symbolically freighted, dramatic, compelling, social creation. The resonance between this present moment and Felicia's past and future emerges even more clearly after interviews with the therapist.

This session is a short story in a larger life story, still very much unfolding, and where the ending is not at all certain. Compare Pocohontas to the fate Penny fears for Felicia. Penny states that Felicia has "self-esteem problems," speaks of herself as looking "yucky." And Penny tells a terrifying story of a meeting between school professionals, hospital therapists, and parents when she meets Felicia's mother for the first time. She describes her as a tall, stern woman who "yells" at all the school and therapy professionals, tells them they do not understand her daughter, and announces she is keeping Felicia for home schooling rather than sending her to school. Felicia, who hangs her head during this meeting, sits in a corner. When Penny must 
leave early, Felicia begs to go with her so that Penny takes her out of the meeting. The therapist also recounts her final session with Felicia (the week after the one we observed) when they just go sit and talk. Felicia, for the first time, talks about her home life in real detail. She, her mother and father, Felicia's two-year-old niece, and two brothers all live in a one-bedroom apartment. The therapist, hand held over her heart, offers her picture of Felicia in a few years. Felicia already is primarily responsible for caring for her niece, a two-year-old left by Felicia's older sister who is never home. The therapist imagines her, the designated family babysitter, eating potato chips and sitting in front of the TV, year in and year out. This is her dark, fearful vision.

Penny is simultaneously helping Felicia address a series of discrete difficulties she faces (for example, paying attention, doing a job well, remembering things, coordinating her physical movements) with a larger project. Penny labels it "building her self-esteem." Certainly that is part of it. But perhaps we could also say that Penny believes Felicia may lack a picture of her future self which is hopeful, which would help guide her in finding the best possible life for herself. Put differently, we might say that Felicia lacks a picture of herself that helps her to see her own possibilities and strengths. Pocohontas may not be a very realistic alternative, but the ability to create Pocohontas, to make with your hands a beautiful magical mirror, such an experience may beget other sorts of creations. One need not accept Penny's version of Felicia's life, but there are many indicators, just in the single session offered here, that this is "an experience" for Felicia. It is not a singular momentous event, like the one described by Sacks, but in its quiet way it presents a striking image which Felicia just may take home.

On the one hand, Penny is confident that she offers something important and unique to Felicia. She tells us she was "that one special person to do something with." Penny, in her early twenties at the time and with a girlish air, believes Felicia saw her as a kind of "friendly older sister." Felicia has also treated her as a protector on occasion; during the one time Penny met Felicia's mother at a team meeting, a woman whose anger frankly frightened Penny, Felicia shrank away, grabbing Penny's hand for comfort. Where is the fragility in this healing drama? Penny lacks conviction that her work has anything to do with healing. She agrees with team members that Felicia should be discharged from therapy. In the end, Penny does not know how to defend her work with Felicia. Perhaps it really was, as she put it, "just a social thing." After all, she readily admits, Felicia's hand writing had not improved in two years, and that was a main treatment goal of their work. She speaks sadly of the plans she and Felicia had made about future therapy together:

We also did a lot of work on the computer because her handwriting was so sloppy and there really wasn't, that was not going to change. That had been worked on for three years and in school everyday. So we started working on the computer and doing typing and hoping that maybe this could be a way that in the future she could be working and, you know, doing a vocational program or something. So, we had talked about doing, making a newspaper which I had started with another one of the day school kids that she knew about.

Not only is Felicia discharged from therapy, Felicia's mother has decided to take her out of the school program. She tells the professional team she wants to give Felicia home schooling instead, a decision that deeply disturbed Penny. In our final interview with Penny, as she spoke of Felicia's future, tears came to her eyes. She was clearly haunted by this case. A year later, Penny decided to leave pediatric practice because she found it just too emotionally difficult.

Penny might have strongly advocated that Felicia stay in therapy, particularly since she was going to be home schooled and would lose most other contact with the world outside her family. Perhaps Penny might not have won this battle, but she does not even try. Furthermore, despite her terrible visions for Felicia's future, she seems to find the recommendations of colleagues 
for Felicia's discharge reasonable. Why? We could go a certain way in answering this by pointing toward a culture of biomedicine in which illness is defined in narrow diagnostic terms, and rehabilitation is identified with well-specified procedures that can be judged against clearly observable, ideally measurable gains in function. But there are more factors at play in the clinical world which support the abandonment of healing dramas, as will be seen shortly.

\section{The Stormy Young Picasso}

Kianu is three and a half. He is a beautiful boy, with the well-defined muscles of a miniature body builder, a readiness to be defiant, and a left arm that hangs down oddly — the legacy of a brachial plexus injury. Such injuries usually occur during birth when the nerves that innervate the shoulder and arm muscles get partially or fully torn from the spinal cord. With this kind of injury, people commonly never gain much use of their damaged arm. Kianu is one of the lucky ones in this respect. He has had a history of therapy sessions and surgery throughout his first three years. He underwent a highly involved, six-hour surgical procedure in which the nerves which had been ripped apart were reconnected. The surgery reportedly went well and the prognosis for better function was good, though the level of recovery depends in part on how much Kianu is willing to use his arm. Even now, postsurgery and successful therapy, his physical impairment is quite noticeable when he walks. His left arm does not move with his body. He still has trouble using his forearm, wrist, and hand. In therapy sessions, he is routinely encouraged to "use lefty" in various kinds of therapeutic tasks. The treatment team now agrees that he has regained most of the function he will have in his arm and he is about ready to be discharged from occupational therapy. His current therapist, Char, has been seeing him for about two months and at the time of the session we describe below, she is getting ready to "wrap up" with Kianu's mother since discharge is imminent.

Kianu was one of the children the therapist, Char, inherited because his previous therapist had changed rotations. She was not happy to have him assigned to her for he was a very "difficult child," she said, a characterization echoed by all the other health professionals who had treated him and also stated by his mother. Over the course of a two-year period, Kianu has worked with at least three therapists. Mary (the researcher) had observed Kianu with each of these therapists, as well as an array of other health professionals. Despite Char's misgivings, the relationship between Char and Kianu was strikingly different. Kianu became a different child with Char for long periods at a time. He became a dancer with her, and a painter as well. His body took on grace and ease, as did his personality. Even his crankiness assumed a certain charm. This clever and charming (if grumpy) Kianu never emerged for long, even with Char, but such a boy had not been as visible in encounters with any of the other health professionals. And, from our knowledge of home life, he did not appear very often there either. Char was able to get Kianu to carry out exercises that others had struggled with, for Kianu had no trouble refusing flatly when he was not interested in cooperating. Commands from his frustrated mother and stern admonitions from professionals would not always sway him.

All in all, Char has found Kianu fascinating, if difficult. Part of Char's success was undoubtedly her broad focus on many aspects of Kianu. When interviewed, she explained that "the arm" was only part, probably not even the major difficulty Kianu was facing in life. Like many of the children in our studies, Kianu was saddled with multiple diagnoses. In addition to brachial plexus, the condition that was the focus of his treatment at this hospital, he had also been given developmental and behavioral diagnoses through his preschool. At the time of this session he was labeled as having "ADD" (attention deficit disorder). The more Char worked with Kianu, the more convinced she became that his learning and behavioral problems were central and that one could not simply "treat the arm" as she had been assigned to do, without simultaneously treating these other problems. 
Without engaging in discussions over the problems and difficulties with such diagnostic categories (which is beyond the scope of this article), the important point here is that Char's success at treatment depends upon her seeing multiple diagnoses and recognizing that she could not simply treat the arm in isolation. But even more important, her ability to attend to Kianu is not simply a matter of seeing him as a child riddled with disabilities and pathologies. She is uncannily capable of seeing his possibilities and strengths and it is this therapeutic competence, as well as her sensitivity to his weak areas, that helps her to create dramas with Kianu in which he emerges as a young Picasso.

Here is a portion that reveals this in no more than 15 minutes of a single session between Char and Kianu. The session takes place in the middle-sized treatment room of the hospital, one of several rooms which are part of the outpatient OT/PT treatment unit. The room itself, which can comfortably fit about five people, is usually reserved by a therapist who wants to treat a child without other treatment sessions going on simultaneously. It is preferred especially when working with children who have a difficult time concentrating on a task and are easily distracted by the presence of other children. The floor is covered with bright blue mats, and many of the key activities are located a foot or two above the mats: a small yellow table with matching yellow plastic chairs, a small swing for toddlers, a big red ball like an oversized balloon, upon which infants are sometimes stretched and rolled. Therapists and parents often kick off their shoes and settle on the mats on the floor along-side the children. There are toys in corners of the room and more toys are stored in cupboards that line most of the walls.

Char and Kianu engage in a hilarious play at the start of the session in which they metamorphose into dinosaurs, "make dinosaur noises," and crawl about the floor. Dinosaurs are a frequent object of attention in this particular ward. Many of the children are enthralled by them and Kianu is no exception. Mia, Kianu's mother, watches while sitting on one of the small children's sized chairs in a corner of the room. Mary sits on a mat in another corner, taking notes.

Having done their dinosaur dance (good for exercising his left arm and shoulder), Char organizes Kianu for some drawing, another favorite activity for him. Kianu generally has a difficult time moving from one activity to another, prone at such moments to high energy explosions in which he throws things or just generally runs amok, spinning out of control. Char, particularly adept at handling this, has settled him quickly at the small yellow table with paper and some colored pens. She sits directly across from him, eye to eye. She treats him as someone much older than his three years, often speaking to him as one might to an adult. He is using his right hand to draw but she has asked him to use his left hand to hold the paper, which he does. Kianu tells her he is drawing eyes. He uses a blue pen, though he himself is dark skinned and his eyes are brown. She asks: "What else is blue?" She shows him a blue peg she is already holding. He replies distractedly but he is busy drawing something. "What's that?" Char asks. Kianu: "It's a zoose." Char laughs. "What's a zoose?" Char looks to his mother for help but Mia shrugs and says "I don't know." Char comments, "I think it's a three-and-a-half-year-old thing." Char and Mia continue to talk while Kianu draws. "He's such a good artist for his age," Char pronounces emphatically. (She is right. Kianu is exceptionally good for a three year old.) Mia concurs, clearly pleased. "Yeah, he practices a lot at home."

Char turns back to Kianu, trying to get him to draw with his left hand. He shrugs her off. She admonishes, "That's your right, dude." At this, he shifts the pen to his left but he cannot figure out how to do it. Heading off impending frustration, Char improvises. She puts his right hand on top of his left hand so he can guide himself. "That's excellent," she encourages. "Can you keep drawing with both hands?" He concentrates, trying hard. Char turns to Mia. "I shouldn't speak so soon but he's focusing very well." These moments are rare, even with Char. Char and Mia look on while Kianu draws. "That's so nice," they call out in unison, a well synchronized 
chorus. Mia adds, “Oh, a flower. That's nice!” This turns out to be an unfortunate remark and the idyllic scene abruptly ends. Kianu slams down his pen, outraged. "It's not a flower!!" he retorts hotly. Char intercedes. "Tell me what it is. I really thought it was a turtle." Kianu tells them disgustedly, "It's a dinosaur." During this prickly interchange, a side drama has been unfolding between Kianu and his mother, a struggle over Kianu's runny nose. Mia wants to wipe it and Kianu wriggles away, preferring to be left alone. Char ignores the runny nose battle, saying something about Stegosauruses while she peers at the drawing, adding, "Look at that dinosaur. He's mean." Kianu immediately contradicts. "He's good!" Everyone bursts out laughing. Good humor is restored.

Char asks, "How old is the dinosaur? Kianu holds up three fingers. Someone begins calling the dinosaur "Ratso" but soon it is no longer clear who is who. Who has the name? Who is three years old - the dinosaur or Kianu? Or both at once? A typical mix-up when imagination lets loose in a pediatric encounter. Kianu picks out a pink crayon for his next drawing project and again Char tries to get him to use both hands. Kianu announces (perhaps to avoid any new conflagration) "I'm gonna make a shoe." He uses his right hand to guide his left, as per Char's instructions. Mia does better as well, commenting, "That's a nice shoe." Kianu then begins another picture, still using both hands in the prescribed manner. Char asks: "What's that?" Mia volunteers, "That looks like batman." Kianu does not reply but he is struggling now to use both hands and suddenly loses his temper. He starts flinging crayons at the wall. Mia is stern. "No throwing." Kianu faces away from the little table, out of Char's line of sight, and glares at his mother. "You're being mean now," he tells her. Mia replies, "You're not playing fair. Please let's turn around." He sits hunched away from the table and his drawing. Mia gets out of her chair, putting her hands on his shoulders to physically turn him around. Things are heating up and Char intervenes with a face-saving maneuver. "Do you want another moment to rest?" Kianu nods, mollified. After a moment he resumes his drawing, even using two hands. Char tells him sympathetically, "I know it's hard to use both hands."

While Kianu draws, Char turns to Mia and begins discussing how she might try to get him to draw with both hands at home, since drawing is so beloved. She shows Mia how to get Kianu to use his left hand on the right side of his body and "stretch out" his left arm and shoulder, suggesting that perhaps "dot to dot" drawings would work for this. They watch Kianu, who is now utterly absorbed in his drawing, head bent over paper. Char tells Mia, "This is a very serious piece of art." Mia agrees, pronouncing, "Kianu will be the next Picasso." While Mia laughs at her own prediction, adding "that would be nice," it is clear she is not altogether joking. Char takes up this hopeful theme, becoming reflective. "I knew this guy in college. I was a dancer. He was a friend of mine who I met through dancing. He had no arms. He used to be able to dance and balance himself without arms." She eloquently expands on this, disclosing more about her own background as a dancer, but Mia interrupts asking when the next appointment will be. With that, Char goes to find a toy car that she will ask Kianu to drive for the final activity of the session.

A few minutes later, when they are ready to leave for the day Char asks Kianu if he would like to take the dinosaur picture home. "No," he replies. "Well then, I'll keep it," she tells him. "Are you gonna tear it up?" Kianu inquires, evidently alert to insincere adult politeness routines. Char laughs, though Mary can't catch her reply.

Char's work with Kianu illustrates the care that practitioners may take in creating therapy moments that reveal the possibilities and potential of a child, even one who has been described in terms of his "volatility," "hostility," "distractability," and "problematic behavior." Like Penny, Char struggles to create moments which illuminate a child's capabilities. There is the problem of exercising that weak left arm, but this problem is embedded in broader goals, ones centered around those frailties and strengths that Char deems more significant than a brachial 
plexus injury. In this encounter there are glimpses of a child who can not only do the usual three-year-old things (crawl like a dinosaur, draw a zoose) but who might even be a future Picasso. Even his storminess is lent a different meaning when guided by this image; not all pathology and disorder, but clues to an artistic sensibility.

How are these possibilities revealed? How do they take on weight and plausibility? It is important that talk is only one modality, perhaps a minor one, through which this image of Kianu is drawn. It is important that these possibilities are embodied and performed, not as a rehearsed and staged drama but as an improvisation where the meaning emerges as events unfold. The drama here involves a metamorphosis in which the usual disturbances are interrupted by calm and creativity. The crayon-slinging boy who careens around treatment rooms, or, (as the therapist says), is ready to "mow down the children in walkers and wheelchairs" as he dashes down the hospital corridors, turns (fleetingly) into a boy whose fierce concentration allows him to make something, to reveal his talents. The drama involves three actors in a precarious dance where the hope is a meditative moment, a still life. When these fleeting moments are achieved, Char and Mia can both look on. They emerge as an appreciative audience, witnesses to Kianu's considerable gifts. They can suddenly see Kianu the artist rather than Kianu with a bad arm and over-whelming behavioral disorders.

This second sight is the heart of the drama. The moral of the emergent story is a transformation in vision. Such a transformation is a dramatic event because it is not merely passively observed, it must be actively created. Just as one might clear a path to catch the view, Char, Kianu, and Mia clear a space, a calm moment, in which a particular scene can unfold. Which is no more than this: Kianu bent over his task, drawing with care and dexterity, proud of his prowess. Even Kianu seems to sense what is at stake. After the dinosaur fiasco, he makes sure to announce he is drawing a shoe beforehand, thus preventing other upsetting misunderstandings. Perhaps his dinosaurs are mistaken for flowers, and his drawings, as he astutely recognizes, will soon be thrown away. But he seems temporarily captured by his own power, or perhaps by a kind of self-forgetting in which he exults in the colors themselves and what one can make with them.

As Penny does with Felicia, Char embeds certain activities directed to discrete disabilities (lack of fine motor coordination for Felicia, an impaired left arm for Kianu) within an activity that she knows the child finds absorbing. And in both cases, the most intense moments are dramatic in their quietude. Time slows. Within this pause, it is possible to glimpse a different child. This glimpse is intensely in the present, which takes on its own authority. But the very intensity of the present facilitates a foreshadowing gaze. This is not a predictive gaze so much as a freewheeling speculation; Felicia enters the body of an Indian princess and Kianu's indecipherable colorings are transmuted into the genius out-pourings of a renowned painter. These are not realistic images. But as with many non-Western healing rituals, their very fancifulness lends them power and intensity - even a certain seductive authority. Perhaps Felicia will find her way out of a dark apartment and a life of babysitting. Perhaps Kianu will emerge from an isolated, angry world where he is already weighted down not merely with a physical disability, but with the label a "special education child."

We do not know what has happened to Felicia but we do know something about Kianu, and it indicates that these small dramas may have a lasting effect. We discovered that a year after Kianu's discharge from therapy, his mother Mia had not forgotten this picture of her son. Mia's children often worry her, especially Kianu and his brother Keon. Mia has continued to encourage Kianu to draw at home, which Char has advocated, but he still has stormy tantrums. One day, nearly a year after discharge from occupational therapy, Mia mentioned, casually, just in passing and with a laugh, that Kianu still loves drawing. He just may be another Picasso, she added. A month later, he was rediagnosed as "gifted" by the school team. This renaming has carried utterly important practical consequences. He has been reassigned from a special 
education classroom, where he had been floundering and generally causing trouble, to a "gifted class" where, as of the time of this writing, he has been thriving. Life is complex and it would be foolish to presume these few months of occupational therapy sessions with Char as pivotal to this turn in Kianu's fortunes. But at the very least, it is clear that Char helped Kianu and his mother to realize an image that is mostly hidden by his wild behavior, his sudden flares of anger, his defiance of everyone around him.

One plausible story to tell about Kianu and Char is that Char played a vital role in Kianu's current success. She saw something in this child at a time when few others did. Better, and more important, she could use what she saw or guessed about him to help create dramas in which this picture was embodied, was made evident to everyone, mother, researcher, or Kianu. But fragility is everywhere. There is a darker sub-text for Kianu, as for many of the African American children in our studies. Most of them do not get "discovered" and given the resources and status of a gifted child. Many parents are not able, as Mia does, to hold on to an image of a child's capabilities in the face of daily power struggles with an easily outraged child. Mia has her own difficulties and can only offer so much to Kianu. Her husband was killed a few years earlier in a store robbery while going to pick up some milk. This tragedy has, among other things, created a harsh financial situation for the family. Mia herself has had a series of illnesses. It is not clear how long things will go well for Kianu. He could easily be reassessed with all the learning and emotional disabilities he was first assigned and be placed back into a special education classroom.

There are two obvious things Char might have done to increase Kianu's chances of success that she fails to do. She might have argued to the treatment team that treatment should be extended in light of Kianu's considerable behavioral and learning disabilities. She might also have helped Mia to get a referral to another clinic that could continue treatment along the lines Char had begun. Although she gives Mia a phone number for another agency, she provides little detail about the process and seems quite neutral in her commitment to promoting the referral. These failures are very like Penny's, failures of omission one might say, in which the charmed and potent experiences created in therapy are readily relinquished. Char does not know many of the details of Mia or Kianu's life, but when she treated him, she was well aware that she was able to "get something" from Kianu that others were not seeing, not able to evoke. She was fearful that he would not receive what he needed in school to help him grow and find his strengths.

And yet, for all her clear foresight and understanding, for all her brilliant work with this child, there is a fragility that surrounds her interventions. While she recognizes her success, she does not challenge the decision of the treatment team that Kianu should be discharged. She does not explain to her supervisor or others on the team what she has been able to accomplish with Kianu in therapy. Neither does she effectively communicate to Kianu's mother Mia the possibility for continuing therapy at another excellent site, one renowned for creative therapeutic approaches (very like those Char has used) that are highly successful with emotionally difficult children. On Kianu's next to last visit with Char, Char mentions this possibility to Mia briefly, but with so little emphasis that it is not clear Mia even heard her suggestion. If Char can do all this with Kianu, why not more? Why does she give up without a struggle, or without even giving clear direction to Mia, a mother who is very committed to therapy and to providing resources for her child, as Char herself notes? What is it about the clinic culture that propels these two different therapists, working in two different cities, to cultivate and then abandon the healing dramas they set in motion? 


\section{THE SUPRESSION OF HEALING DRAMAS IN PEDIATRIC PRACTICE}

The healing dramas we have described very often pass unnoticed or are abandoned by their creators for a number of reasons directly connected to the culture of the clinical world. Most obvious is the organizing role of the diagnosis in framing what constitutes appropriate treatment. The cases of Kianu and Felicia (with their multiple disabilities) reveal a hierarchy among diagnostic categories, with some diagnoses more "real" and more deserving of clinical attention than others. The power of any particular diagnosis is not necessarily linked to its impact on a patient's overall health, but rather on its symbolic (and economic) capital. This, in turn, is closely linked to another kind of hierarchy - the power and ranking of the diagnostician who has "awarded" the diagnosis to a particular patient. Kianu's situation illustrates: here is a boy whose behavioral problems have a far greater negative impact on his life than his brachial plexus injury. However, the behavioral and emotional disabilities have been diagnosed by school psychologists and occupational therapists while his brachial plexus injury is the province of the much higher-status orthopedic surgeon.

Technology and specialized training play a key part in determining the symbolic capital of any given diagnosis. Anthropologists have repeatedly underscored the technology-driven nature of Western biomedicine and the insidious ill effects of health care that is built around such technology (Davis-Floyd and Davis 1996; Jordan 1993). Psychologists and therapists practice comparatively "low-tech" medicine, but the surgery involved in repairing a brachial plexus injury is extremely intricate. Kianu's surgeon, Dr. Crane, is nationally renowned for his skill in this particular type of surgical procedure. Although, as the surgeon readily admits, rehabilitation (those low-technology interventions offered by therapists) is critical to the functional outcome of the surgery, it is the surgery itself that lends this diagnosis its status and makes Kianu a candidate for treatment at this well-respected hospital rather than a local community clinic. The institutional hierarchy may set rehabilitation therapists such as Char (with her concern over comparatively low-status diagnostic problems) against much more powerful professionals.

Notably, the kind of rehabilitation program surgeons such as Dr. Crane have in mind do not involve the playful, imaginative, and dramatic moments which therapists like Char excel at creating. In fact, Dr. Crane remarked to us that he was continually waging a battle with the rehabilitation therapists to put in more of their time doing "stretching" and other exercises directed at the injured site rather than spending their time "merely playing" with children. What we saw as effective drama, the creation of a healing experience that did much more than allow Kianu to stretch his hampered left arm, Dr. Crane saw as "just play." The difficulty is not simply that from the institutional perspective, Char should not be focusing on Kianu's behavior. There is a concern among physicians that rehabilitation therapists focus on goals directly tied to the surgeries. Surgeons are, in this sense, dependent on the actions of the lower-status professionals and patients themselves for their surgeries to be successful. When interviewed, Kianu's surgeon stated that good recovery routinely depends on "70 percent on rehabilitation" and "30 percent on surgery," no matter how skilled the physician.

So while, from Char's perspective, emotional disabilities may prove his greatest health risk, from a more powerful institutional perspective, embodied here in Dr. Crane, the success of the surgery is of the highest importance. Char may see these two as interrelated (she cannot "get to the arm," as she complains, without "treating the behavior") but given that Kianu's arm is, in fact, much improved, she cannot use the behavioral diagnoses to argue for continued treatment. Institutionally, Dr. Crane's perspective is honored far above Char's because the entire structure of the hospital is organized to privilege expensive, high-technology interventions. It routinely receives some of the most medically complex cases in the state. It is the surgeries of a Dr. Crane, who has been on local news more than once, rather than the 
healing dramas facilitated by Char, that provide this hospital its regional reputation as an excellent clinical site.

The link between healing and technology in Western biomedical practices becomes evident in a different sense when one looks at those health care practices where the "hands on" skill of the professional is the primary tool for treatment. Biomechanical metaphors apply not merely to the body of the patient, but also to the healer as well. Rehabilitation therapists are often viewed, and view themselves, as technicians of the body, as interchangeable providers of technical interventions. Key decisions about intervention are often made apart from what the actual healer might determine as necessary, as when Char "inherits" Kianu at a time when it has already been fixed that he will soon be discharged.

There is also the valorization of the routine against the dramatic within clinic culture. Surgeries, like some of those performed by Dr. Crane, may attract television coverage, but as anthropologists have pointed out, modern clinics are organized in a way to make even the newest and most experimental interventions appear routine. Biomedical practices are carried out in an institutional atmosphere of routineness. Medical professionals find ways to routinize their practice and thus, metaphorically at least, bring the unruly and frightening world of illness under control. Illness is, by nature, an unpredictable thing and much of medicine is fraught with uncertainty (Becker 1994; Hunter 1991). The need to control illness is an endemic issue (Becker and Kaufman 1995; Rhodes 1993). In biomedical practices, argue Davis-Floyd and Davis, "A reassuring cultural order is imposed on the otherwise frightening and potentially out-of-control chaos of nature" (1996:238).

Perhaps nowhere is this penchant for the mundane more evident than in the authorized treatments performed by rehabilitation therapists. Here, the predictable intervention constitutes what is publically reportable and reimbursable. The dramatic, by contrast, constitutes an "underground practice" among therapists—-what they sometimes do, and even sometimes cherish, but rarely publically admit or defend (Mattingly and Fleming 1994; Mattingly 1998). There will be no reports by Char of dancing dinosaurs or the fleeting appearance of a budding Picasso in the medical chart. In the public discourse of the rehabilitation clinic, the individualized, improvisational, and imaginative is always suppressed in the name of repeatable routines. Even physicians, such as Dr. Crane, who are themselves keenly aware that they must build trusting relationships with patients and families, and in this sense "individualize" certain aspects of their practice, protest when therapists do not follow strict routines in their treatment protocols.

In rehabilitation therapies (dominated by the physical/occupational/speech triad), routinization is accomplished through a focus on relearning bodily skills that are very often treated as disconnected from a person and her life. However, rehabilitation has some special features that distinguish it from many other clinical encounters. While patients are very often required to be passive within the hospital, to wait, to lie still, to render their bodies docile and inert, rehabilitation asks something quite different. Rehabilitative professionals demand active patients. Docility here takes the form of hard work, a daily struggle with one's body. And practitioners themselves are also active, assessing a patient's status, etiology, and prognosis by attending to bodies in motion, seeing what they can do, and by moving their own bodies in ways that facilitate the movements of their patients. When patients are in rehabilitation, they are involved in "doing therapies" where actions, often everyday actions, form the core of treatment (Mattingly 1998).

In spite of the fact that therapists are generally unwilling to report deviations from the routine, many therapists resist reducing their interventions in narrowly biomechanical terms, even though their resistance may not take them far. Their rebellion is sometimes propelled by the 
patients, particularly in pediatrics. Children like Kianu and Felicia tend to refuse to cooperate with painful or boring routines, and many therapists are unwilling to treat a screaming, tantrumthrowing or sullenly catatonic child for 45 minutes. Some therapists, like Char, are also inspired by a vision of effective practice that demands embedding routine exercises within imaginative activities-in other words, some kind of creative play.

Perhaps the most powerful impediment to the recognition and cultivation of healing dramas within the modern clinic has to do with the disconnection between what healers like Char or Penny believe, in an almost private way, to be important for a given patient and what they feel they can legitimately claim to know. Their claims to authoritative knowledge do not include the capacity to redirect treatment to tackle diagnostically diffuse emotional and behavioral problems of their patients, especially not when treatment looks, as Penny remarks dejectedly, like "just a social thing." Turf issues and a myriad of other institutional factors stand between these healers and their own "personal knowledge," to use Michael Polanyi's important term. In such situations, Western biomedicine, with its particular claims to authoritative knowledge, not only undermines confidence in the embodied knowledge of sufferers (Browner and Press 1995; Jordan 1993; Sargent and Bascope 1996) but also of the healers themselves. Yet the cultivation of healing dramas in which, for instance, Kianu can reveal his artistic talents, or Felicia her wit and charm, demand that healers draw upon their own embodied knowledge. Char, for example, draws upon her own experience as a dancer to notice the capabilities already evident in Kianu's three-year-old body. Looking back at her treatment of him, she said, "To me, what was really interesting about him is his movement. Like, I just was fascinated with his body, from being a dancer, how he adapted himself. ... I don't know, he's just like a beautiful athlete that, you know, has this handicap but uses it quite well." Though he was such an angry child, Char saw him as "really gifted ... with the art, with the movement" and she tried to capitalize on this in her therapy, to bring these gifts to public light. To do so, she also needed the flexibility to follow leads provided by Kianu himself. Adhering to a strictly prescribed routine is antithetical to the kind of therapeutic attention demanded in creating such healing dramas.

\section{CONCLUSION}

Beneath the highly visible machinery of the modern clinic, with its elaborate technology, mindnumbing routinization, and cool dispassion, all sorts of other strange and even miraculous healing dramas may spring up, and in the most unlikely ways. Some of these are precipitated by patients or their families, some are even created in league with professionals themselves. In these narrative moments, recovery may not mean regaining the faculties one once had, but it does mean reclaiming a body, discovering where and how movement is possible. In such moments, exercises and other therapeutic tasks emerge as healing dramas. These dramas may be hidden from professional view, as Sacks relates in his own case. Or they may be discounted by professionals, not seen as fundamental to healing. Whether professionally recognized or ignored, these dramas share certain common features. They concern moments experienced by the participants as significant, time in which something is at stake. This "at stakeness" transforms mere experience, the forgettable everyday, to "an experience" with narrative form. In other writing, Mattingly $(1994,1998)$ has used the construct "therapeutic emplotment" to designate those moments in which a dramatic figure is shaped in time itself. Healing, in a practice like occupational therapy at least, very often involves creating activities imaginatively rich enough to convey the moral that, despite a body lost, broken or largely silent, there still exists a self worth making, worth struggling for. Morals are embodied in actions themselves and in the dramas that surround taking action when a body (and a self) is threatened. But not just any sort of action will do. 
The clinical actions that create dramas, those with transformative and healing potential, must matter deeply to the patient. They must call to the body. Very often they are part of a body knowledge, a powerful, highly valued, ingrained, and tacit mode of being in the world. Experience itself becomes the focus of attention for the patient. The body may have its techniques, practices, efficiencies, and breakdowns that can be neatly rendered and reasoned about in those mechanical metaphors that abound in rehabilitation. But in these moments, such qualities are taken up in the experience of movement itself, and movement towards something, movement for something, movement of no mere material matter but of one's very self. Healing dramas within the world of rehabilitation have a public, socially constructed character. They are rather like improvisational plays involving multiple characters, each finding their parts and cuing one another about what ought to happen next. These dramas are very much created between therapists and patients, and family members as well, so that it is clear that significant experience is not something that is merely privately felt and intuited but something that exists in the public world. In depicting his own recovery from a leg injury, Sacks tells a story that insists on the centrality of drama to healing, where drama is understood in deeply phenomenological terms, an experience of the body, one where the body is vividly marked as the "seat" not only of experience but also of self identity. In these dramatic moments, the body is experienced in a different way. It is transformed from impediment and obstacle to a site of possibility. Experience takes the shape of an imaginary journey from illness to recovery, even if, as is often the case, it does not lead to any medical cure.

Healing dramas may be powerful, but they may also be fleeting, momentary bursts of life that cannot be sustained under a harsh clinical gaze. They are fragile things, often created only to be interrupted, ignored, or undermined. It may sometimes be the case, as Van Blerkom argues in his study of "clown doctors," that "Western medical practitioners increasingly recognize the need to escape the limitations of a bioreductionist view of health and disease" (1995:465). Among the rehabilitation therapists we have studied, however, we have not found an ability among practitioners to accommodate to different models of healing simultaneously or to see them as complimentary. Rather, we have witnessed a deep unease as practitioners initiate healing dramas that they then feel forced to relinquish when their treatment approach departs too visibly from authorized clinical care.

In this article, we have offered an anatomy of two such moments of initiation and abandonment within the world of pediatric rehabilitation. The significance of the experiences created is fragile and easily lost not only because lived experience necessarily has a fleeting quality but because the cultural worlds in which these experiences occur do not authorize these kinds of healing dramas. They have no official status within clinic culture for they are not acknowledged as integral to healing. When Sacks's experiences of recovery are not shared by his healers, he improves anyway. He recovers both his leg and his life. As it turns out, his healing is not dependent on his healers' recognition of the dramas of recovery. Felicia, Kianu, and the other children in our studies are not so lucky. They are not blessed with the resources Sacks draws on, and their injuries and illnesses are far more serious. Felicia and Kianu do encounter healers who seem to recognize, at some level, that healing in the world of chronic illness and disability requires the creation of significant moments, those that reveal possible worlds and possible selves worth striving for. But the dramas of recovery we have explored in their cases, created in concert with the therapists themselves, are constructed within the confines of institutional worlds. Such worlds largely constrain these professionals' vision of their task. When healing dramas are not sufficiently prized, healing falters or fails altogether. Sacks preserves and recreates his experience through his storytelling powers and his own practice as a physician. But it is less clear that Felicia and Kianu will be able to emplot their lives such that these dramatic moments become episodes in a larger and longer lasting drama of recovery. 


\section{Acknowledgments}

The research described in this article was supported by grant MCJ-060745 from the Maternal and Child Health Program (Title V, Social Security Act), Health Resources and Services Administration, Department of Health and Human Services. We would like to thank the participants, both families and clinicians, who have allowed us to study their lives.

\section{REFERENCES CITED}

Becker, Gay. Metaphors in Disrupted Lives: Infertility and Cultural Constructions of Continuity. Medical Anthropology Quarterly 1994;8:383-410.

Becker, Gay; Kaufman, Sharon R. Managing an Uncertain Illness Trajectory in Old Age: Patients' and Physicians' View of Stroke. Medical Anthropology Quarterly 1995;9:165-187. [PubMed: 7671113]

Briggs, Charles. The Meaning of Nonsense, the Poetics of Embodiment, and the Production of Power in Warao Healing. In: Laderman, C.; Roseman, M., editors. The Performance of Healing. London: Routledge; 1996. p. 185-232.

Browner, Carole H.; Ann Press, Nancy. The Normalization of Prenatal Diagnostic Screening. In: Ginsburg, FD.; Rapp, R., editors. Conceiving the New World Order: The Politics of Reproduction. Berkeley: University of California Press; 1995. p. 307-322.

Bruner, Jerome. Actual Minds, Possible Worlds. Cambridge, MA: Harvard University Press; 1986.

Bruner, Jerome. Act of Meaning. Cambridge, MA: Harvard University Press; 1990.

Bruner, Jerome. The Narrative Construction of Reality. Critical Inquiry 1991;18:1-21.

Carr, David. Time, Narrative, and History. Bloomington: Indiana University Press; 1986.

Carr, David. Narrative and the Real World: An Argument for Continuity. In: Hinchman, LP.; Hinchman, S., editors. Memory, Identity, Community: The Idea of Narrative in the Human Sciences. New York: State University of New York Press; 1997. p. 7-25.

Crites, Stephen. The Narrative Quality of Experience. In: Hinchman, LP.; Hinchman, S., editors. Memory, Identity, Community: The Idea of Narrative in the Human Sciences. New York: State University of New York Press; 1997. p. 26-50.

Csordas, Thomas J. Introduction: The Body as Representation and Being-in-the-World. In: Csordas, Thomas J., editor. Embodiment and Experience. Cambridge: Cambridge University Press; 1994. p. $1-24$.

Csordas, Thomas J. Imaginal Performance and Memory in Ritual Healing. In: Laderman, C.; Roseman, M., editors. The Performance of Healing. London: Routledge; 1996. p. 91-113.

Danforth, Loring. Firewalking and Religious Healing: The Ana Stenari of Greece and the American Firewalking Movement. Princeton: Princeton University Press; 1989.

Davis-Floyd, Robbie; Davis, Elizabeth. Intuition as Authentic Knowledge in Midwifery and Home Birth. Medical Anthropology Quarterly 1996;10(2):237-269. [PubMed: 8744086]

Desjarlais, Robert. Presence. In: Laderman, C.; Roseman, M., editors. The Performance of Healing. London: Routledge; 1996. p. 143-164.

Dilthey, William. Introduction to the Human Sciences. In: Makkreel, RA.; Rodi, F., editors. Selected Works. Vol. vol. 1. Princeton: Princeton University Press; 1989.

Gadamer, Hans-Georg. Truth and Method. New York: Seabury Press; 1975.

Hughes-Freeland, Felicia. Introduction. In: Hughes-Freeland, Felicia, editor. Ritual, Performance Media. London: Routledge; 1998. p. 1-28.

Hunter, K. Doctor's Stories: The Narrative Structure of Medical Knowledge. Princeton: Princeton University Press; 1991.

Jackson, J. Paths toward a Clearing: Radical Empiricism and Ethnographic Inquiry. Bloomington: Indiana University Press; 1989.

Jordan, Brigitte. Birth in Four Cultures: A Cross Cultural Investigation of Childbirth in Yucatan, Holland, Sweden and the United States. 4th ed.. Prospect Heights, IL: Waveland Press; 1993. [1978]

Kapferer, B. A Celebration of Demons: Exorcism and the Aesthetics of Healing in Sri Lanka. Bloomington: Indiana University Press; 1983. 
Kapferer, B. Performance and the Structuring of Meaning and Experience. In: Turner, V.; Bruner, E., editors. The Anthropology of Experience. Urbana: University of Illinois Press; 1986. p. 188-203.

Kendall, L. Initiating Performance: The Story of Chini, a Korean Shaman. In: Laderman, C.; Roseman, M., editors. The Performance of Healing. London: Routledge; 1996. p. 17-58.

Laderman, C. The Poetics of Healing in Malay Shamanistic Performances. In: Laderman, C.; Roseman, M., editors. The Performance of Healing. London: Routledge; 1996. p. 115-147.

Maclntyre, Alisdair. After Virtue: A Study in Moral Theory. South Bend: University of Notre Dame Press; 1981.

Mattingly, Cheryl. The Concept of Therapeutic "Emplotment". Social Science and Medicine 1994;38:811-822. [PubMed: 8184332]

Mattingly, Cheryl. Healing Dramas and Clinical Plots: The Narrative Structure of Experience. Cambridge: Cambridge University Press; 1998.

Mattingly, Cheryl. Emergent Narratives. In: Mattingly, Cheryl; Garro, L., editors. Narrative and the Cultural Construction of Illness and Healing. Berkeley: University of California Press; 2000. p. 181-211.

Mattingly, Cheryl; Fleming, Maureen. Clinical Reasoning: Forms of Inquiry in Therapeutic Practice. Philadelphia: F. A. Davis; 1994.

Olafson, Frederick. The Dialectic of Action: Philosophical Interpretation of History and the Humanities. Chicago: University of Chicago Press; 1979.

Polkinghorne, DE. Narrative Knowing and the Human Sciences. Albany: State University of New York Press; 1988.

Rhodes, L. The Shape of Action. In: Lindenbaum, S.; Lock, M., editors. Knowledge, Power and Practice. Berkeley: University of California Press; 1993. p. 129-144.

Ricoeur, Paul. Time and Narrative. McLaughlin, K.; Pellauer, D., editors. Vol. vols. 1 and 2. Chicago: University of Chicago Press; 1984. trans.

Ricoeur, Paul. Time and Narrative. Blarney, K.; Pellawer, D., editors. Vol. vol. 3. Chicago: University of Chicago Press; 1987. trans.

Sacks, Oliver. A Leg to Stand On. New York: Summit Books; 1987. [1984]

Sargent, Carolyn; Bascope, Grace. Ways of Knowing about Birth in Three Cultures. Medical Anthropology Quarterly 1996;10(2):213-236. [PubMed: 8744085]

Schechner, Richard. Magnitudes of Performance. In: Schechner, Richard; Willa, A., editors. By Means of Performance: Intercultural Studies of Theatre and Ritual. Cambridge: Cambridge University Press; 1990. p. 19-49.

Schieffelin, Edward. On Failure and Performance: Throwing the Medium Out of the Seance. In: Laderman, C.; Roseman, M., editors. The Performance of Healing. London: Routledge; 1996. p. 59-89.

Stern, Daniel N. One Way to Build a Clinically Relevant Baby. Infant Mental Health Journal 1994;15 (1):9-25.

Stern, Daniel N. The Motherhood Constellation. New York: Basic Books; 1995.

Stoller, Paul. The Taste of Ethnographic Things: The Senses of Anthropology. Philadelphia: University of Pennsylvania Press; 1989.

Stoller, Paul. Sounds and Things: Pulsations of Power in Songhay. In: Laderman, C.; Roseman, M., editors. The Performance of Healing. London: Routledge; 1996. p. 165-184.

Stoller, Paul. Sensuous Scholarship. Philadelphia: University of Pennsylvanian Press; 1997.

Tambiah, Stanley. Culture, Thought and Social Action: An Anthropological Perspective. Cambridge: Cambridge University Press; 1985.

Turner, E. Experiencing Ritual: A New Interpretation of African Healing. Philadelphia: University of Pennsylvania Press; 1992.

Turner, Victor. The Ritual Process: Structure and Anti-Structure. Chicago: Aldine; 1969.

Turner, Victor. The Anthropology of Performance. New York: PAJ Publications; 1986a.

Turner, Victor. Dewey, Dilthey, and Drama: An Essay in the Anthropology of Experience. In: Turner, Victor; Bruner, EM., editors. The Anthropology of Experience. Chicago: University of Illinois Press; 1986b. p. 33-44. 
Van, Blerkom; Miller, Linda. Clown Doctors: Shaman Healers of Western Medicine. Medical Anthropology Quarterly 1995;9(4):462-475. [PubMed: 8748473] 